\title{
Limbic encephalitis as the presenting feature of Sjögren syndrome
}

\author{
Pasquale F. Finelli, MD \\ Violiza Inoa, MD
}

A

27-year-old woman was transferred to our hospital for further evaluation of progressive gait difficulty, slurred speech, right hand tremor, and temporal lobe lesion. She was in her usual state of good health until 1 year earlier when she developed right hand next 6 months and significant dysarthria and right hand weakness and intention tremor was noted. Her penmanship was illegible, tandem gait was impaired, and rapid alternating movements with the right hand were slow compared to the left. A dilated left pupil was diagnosed as an Adie tonic pupil. MRI showed a small area of increased signal on fluid-attenuated inversion recovery (FLAIR) sequence in the right temporal lobe. She was readmitted because of falls, progressive cognitive impairment, gait ataxia, dysarthria, and right hand tremor. On gait testing, she could only walk with the assistance of 2 aides. Because of increased size of the right temporal lobe lesion on repeat MRI, she was transferred to our hospital for consideration of brain biopsy.

At our hospital, she now manifested rapid, conjugate, random eye movements. Laboratory studies including complete blood count, routine blood chemistries, and liver function tests were all normal except for a white blood cell count of $2,100 / \mu \mathrm{L}$. Sedimentation rate was 38 $(0-20 \mathrm{~mm} / \mathrm{h})$, rheumatoid factor was $92 \mathrm{IU} / \mathrm{mL}(\mathrm{n}<14)$, and antinuclear antibody was 1:640 with speckled pattern. Lyme Western blot, HIV, neuromyelitis optica-AQP4, and angiotensin converting enzyme were normal or nonreactive. Serum ceruloplasmin level was $29(20-60 \mathrm{mg} / \mathrm{dL})$. Spinal fluid paraneoplastic antibody panel including NMDA, GAD65, VGK channel antibody, antineuronal nuclear antibody type 1,2, and 3, antiglial nuclear antibody type 1, Purkinje cell cytoplasmic type 1,2, and Tr antibody, amphiphysin antibody, CRMP-5, anti Yo, and anti-Hu.

Acetylcholine receptor (ganglionic neuronal and muscle) and calcium channel antibodies were negative. CSF showed 12 white blood cells, $80 \%$ of which were monocytes, protein was $89 \mathrm{mg} / \mathrm{dL}$, a viral panel screen and bacterial cultures were negative. CT of the chest, abdomen, and pelvis and whole-body PET scan were negative for malignancy. EEG showed diffuse slowing of the background. MRI showed progression of lesions including brainstem and cerebellar involvement (figure, A, B). Anti-Ro/SSA and anti-La/SSB antibodies were both elevated to $>100 \mathrm{EU}(\mathrm{n}=0-25)$.

Schirmer test was positive for reduced tear production and lip biopsy (figure, C) demonstrated features characteristic of Sjögren syndrome (SS). IV immunoglobulin (IVIg) $25 \mathrm{~g} /$ day was given for 5 days and over the next 6 weeks the patient showed slow improvement of speech, hearing, fine motor and head control, and ambulation. She was discharged, ambulatory

Department of Neurology, Hartford Hospital and University of Connecticut School of Medicine, Hartford.

Correspondence to: pfinell@harthosp.org 


\section{Figure Imaging and biopsy}
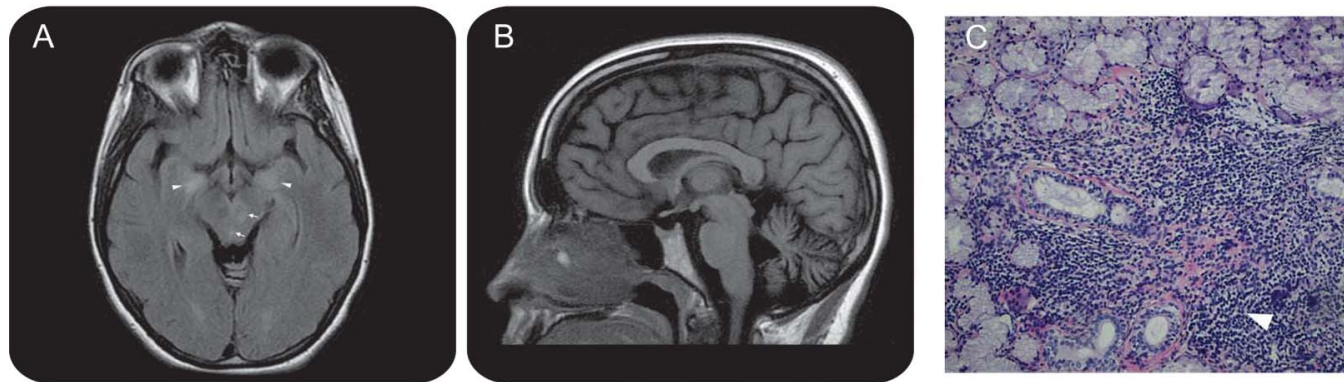

(A) Fluid-attenuated inversion recovery (FLAIR) imaging shows hyperintensity of mesiotemporal lobe, right more than left (arrowheads), and left midbrain (arrows). (B) Sagittal T1-weighted FLAIR shows atrophy of cerebellum. (C) Labial salivary gland biopsy shows multiple lymphocytic foci of greater than 50 lymphocytes $/ 4 \mathrm{~mm}^{2}$ of tissue (arrowhead) (hematoxylin \& eosin $\times 40$ ).

with the use of a walker and one assistant, to an acute rehabilitation facility after a 10-week hospitalization.

\section{DISCUSSION}

SS is an autoimmune disease, the diagnosis of which is made difficult by the varied clinical presentation that results from multiple organ system involvement. The syndrome is characterized by mononuclear infiltrate and destruction of salivary and lacrimal glands leading to xerostomia and xerophthalmia. Similar mononuclear infiltrate involving visceral organs or vasculitic lesion may result in extraglandular manifestations. ${ }^{1}$ Nervous system complications occur in $20 \%$ $25 \%$ of patients with only some $6 \%$ involving the CNS. ${ }^{1,2}$ In more than $50 \%$ of patients with CNS SS nervous system findings precede systemic manifestations. Neurologic manifestations are protean, as seen in our patient, whose clinical picture included gait ataxia, hearing loss, tremor, cognitive impairment, opsoclonus, Adie pupil, and pleocytosis. ${ }^{1-4}$ In our patient the cognitive, coordination, ataxic, and eye movement disorder findings are reflective of the mesiotemporal lobe, brainstem, and cerebellar MRI FLAIR abnormalities described, yet strict correlation is imprecise considering SS can affect any level of the neuraxis with normal MRI seen in as many as $30 \%$ of confirmed cases.

Sicca syndrome is present in only $50 \%$ of patients with neurologic involvement and anti-Ro/SSA and anti-La/SSB antibodies are positive in only $50 \%$ of patients with SS with and without nervous system involvement during the course of the disease. MRI findings are reported in up to $70 \%$ of patients showing white matter lesions that closely resemble those seen with multiple sclerosis. ${ }^{1}$

An isolated temporal lobe lesion on MRI was the sole abnormality on the initial neuroimaging of our patient. Recognizing the association of MRI FLAIR-defined temporal lobe lesion with limbic encephalitis (LE) should prompt further evaluation for a paraneoplastic and autoantibody-related process including SS. A prior case of LE in a patient with asymmetric cerebellar syndrome with SS has been described ${ }^{5}$ with MRI findings confined to one temporal lobe.

Lip biopsy, with characteristic pathologic features in conjunction with a positive Schirmer test and serology, fulfill the revised American-European diagnostic criteria for primary SS, ${ }^{6}$ helpful in supporting long-term treatment with IVIg and immunosuppressive therapy shown beneficial with neurologic involvement in SS.

\section{REFERENCES}

1. Delalande S, deSeze J, Fauchais AL, et al. Neurologic manifestations in primary Sjögren's syndrome: a study of 82 patients. Medicine 2004;83:280-291.

2. Massara A, Bonazza S, Castellino G, et al. Central nervous system involvement in Sjögren's syndrome: unusual but not unremarkable: clinical, serological characteristics and outcome in a large cohort of Italian patients. Rheumatology 2010;49:1540-1549. 
3. Vermarsch P, Dufourd-Delalande S, Defoort-Dhellermmes S, Stojkovic T, Launay D, deSeze J. Tonic pupils in Sjögren syndrome. Rev Neurol 2005;161:963-966.

4. Averbuch-Heller L, Remler B. Opsoclonus. Semin Neurol 1996;16:21-26.

5. Collison K, Rees J. Asymmetric cerebellar ataxia and limbic encephalitis as a presenting feature of primary Sjögren syndrome. J Neurol 2007;254;1609-1611.

6. Vitali C, Bombardieri S, Jonsson R, et al. Classification criteria for Sjögren's syndrome: a revised version of the European criteria proposed by the American-European Consensus Group. Ann Rheum Dis 2002;61:554-558.

\section{ACKNOWLEDGMENT}

The authors thank Ruth Foster, APRN, who assisted in the care for this patient while hospitalized.

\section{STUDY FUNDING}

No targeted funding reported.

\section{DISCLOSURES}

The authors report no disclosures relevant to the manuscript. Go to Neurology.org/cp for full disclosures.

\section{AAN Store: Your One-Stop Shop for Practice Tools}

Looking for an easy, convenient way to order your practice essentials?

Visit the AAN Store online for an array of quality products backed with our high standards. Save up to 20 percent with your AAN member discount. The AAN Store is your source for diagnostic tools and references, including:

- Exclusive AAN Products (pocket guidelines, coding guides, syllabi on CD, patient education books, and brochures)

- Top-quality Diagnostic Tools (reflex hammers, visual and sensory testing tools, pocket guidelines)

- Educational Resources for You, Your Practice, and Your Patients (CDs, DVDs, books, 3D models, posters, and brochures)

Shop quickly and easily at www.aan.com/aanstore today! 